\title{
Mechanical Ventilation Effect on Surfactant Content, Function, and Lung Compliance in the Newborn Rat
}

\author{
FRANCISCO MARTINEZ, JAMES LEWIS, IAN COPLAND, DOREEN ENGELBERTS, \\ BRIAN P. KAVANAGH, MARTIN POST, SAMUEL SCHURCH, AND JAQUES BELIK \\ Department of Pediatrics, University of Toronto and Canadian Institutes of Health Research Group in \\ Lung Development, Lung Biology and Integrative Biology Programmes, Hospital for Sick Children, \\ University of Toronto, Toronto, Ontario, Canada M5G 1 X8 [I.C., D.E., B.K., M.P., J.B.], Department of \\ Physiology and Medicine, Lawson Health Research Institute, The University of Western Ontario, London, \\ Ontario, Canada N6A 4V2 [J.L.], Department of Pediatrics, University of Sao Paulo, Ribeirao Preto, Sao \\ Paulo, Brazil 14049-900 [F.M.], and Respiratory Research Group, Faculty of Medicine, University of \\ Calgary, Calgary, Alberta, Canada T2N 2T9 [S.S.]
}

\begin{abstract}
ABST
Studies of ventilator-associated lung injury in adult experi-
mental animal models have documented that high tidal volume
(TV) results in lung injury characterized by impaired compliance
and dysfunctional surfactant. Yet, there is evidence that, in
neonates, ventilation with a higher than physiologic TV leads to
improved lung compliance. The purpose of our study was to
evaluate how lung compliance and surfactant was altered by high
TV ventilation in the neonate. We utilized a new model (me-
chanically air-ventilated newborn rats, $4-8 \mathrm{~d}$ old), and used 40
or $10 \mathrm{~mL} / \mathrm{kg}$ TV strategies. Age-matched nonventilated animals
served as controls. In all animals, dynamic compliance progres-
sively increased after initiation of mechanical ventilation and
was significantly greater than basal values after 60 min $(p<$
$0.01)$. Lung lavage total surfactant with both TV strategies $(p<$
$0.05)$ and the large aggregate fraction (only in TV $=40 \mathrm{~mL} / \mathrm{kg}$;
$p<0.01$ ) were significantly increased by 60 min of mechanical
ventilation, compared with control animals. Ventilation with 40
mL/kg TV for 60 min adversely affected the lung surfactant
\end{abstract}
A single stretch of alveolar type II cells causes an increase in cytosolic calcium resulting in stimulation of surfactant secretion for up to $30 \mathrm{~min}$ post stretch (1). In adult animals, this mechanism is operative after an increase in spontaneous breathing tidal volume $(2,3)$, but never demonstrated after short-term mechanical ventilation with a higher than physiologic tidal volume.

Received June 24, 2003; accepted November 27, 2003.

Correspondence: Jaques Belik, M.D., FRCPC, Professor of Pediatrics, University of Toronto, Division of Neonatology, Hospital for Sick Children, 555 University Ave., Toronto, ON, M5G 1X8, Canada: e-mail: Jaques.Belik@SickKids.ca

Supported by grants from the Canadian Institutes of Health and Research.

DOI: 10.1203/01.PDR.0000128980.82797.29 surface-tension lowering properties $(p<0.01)$. After $180 \mathrm{~min}$ of ventilation with $40 \mathrm{~mL} / \mathrm{kg} \mathrm{TV}$, the lung total surfactant content and dynamic compliance values were no longer distinct from the nonventilated animals' values. We conclude that, in the newborn rat, mechanical ventilation with a higher than physiologic TV increases alveolar surfactant content and, over time, alters its biophysical properties, thus promoting an initial but transient improvement in lung compliance. (Pediatr Res 56: 19-25, 2004)
Abbreviations
ARDS, acute respiratory distress syndrome
LA, large aggregate surfactant subfraction
PEEP, positive end-expiratory pressure
SA, small aggregate surfactant subfraction
SP-A, surfactant protein-A
SP-B, surfactant protein-B
SP-C, surfactant protein-C

Isolated adult rat lungs mechanically ventilated with a tidal volume four times higher than physiologic $(25 \mathrm{~mL} / \mathrm{kg})$ for $1 \mathrm{~h}$ showed a decrease in lung compliance (4), which was associated with an increased conversion from LA to SA within the alveolar space (5). These latter changes likely accounted for the reduction in compliance, inasmuch as adequate biophysical activity of surfactant is dependent on a functional LA fraction.

The concept that high tidal volumes may have adverse effects has been consistently demonstrated in multiple animal models of adult ventilator-associated lung injury (6-8). This concept has driven a variety of strategies aimed at reducing tidal stretch, including permissive hypercapnia (9-11), as well as studies designed to limit pressure and volume ventilatory parameters associated with tidal stretch (12-14). Indeed, in 
adult ARDS, this approach has been vindicated with the demonstration that increased tidal volume ventilation is associated with worsened mortality in patients with $\operatorname{ARDS}(15,16)$.

In the neonate, however, the response to short-term ventilation with higher tidal volumes appears to contrast with the adult. Ratjen et al. (17) studied the lung mechanical properties of healthy full-term infants subjected to a few inspiratory efforts with a tidal volume $75 \%$ greater than that observed during regular breathing $(10 \mathrm{~mL} / \mathrm{kg})$. A significant improvement in total respiratory system compliance was observed, and was explained on the basis of recruitment of atelectatic lung units. Yet stretch-induced changes in surfactant synthesis/ release may account for this response because there is evidence that the fetal lung epithelial cells respond to stretch with an increase in surfactant production (18). Although lung recruitment strategies appear to be of clinical benefit in neonates (19), the specific effect of in vivo lung stretch on endogenous surfactant release and/or secretion in neonates has not been studied.

Thus, the purpose of this study was to evaluate the in vivo changes in total respiratory system compliance and the surfactant system in normal newborn rats after mechanical ventilation with 10 and $40 \mathrm{~mL} / \mathrm{kg}$ tidal volume strategies. We hypothesized that ventilation with 10 , but not $40 \mathrm{~mL} / \mathrm{kg}$ tidal volume results in lung surfactant release and/or secretion and improved lung compliance.

\section{METHODS}

Animal preparation. Newborn Sprague Dawley rats aged 5-8 d kept with their dam until the day of the experiment were used. The animals were sedated with an intraperitoneal injection of a mixture of xylazine and ketamine $(8$ and $80 \mathrm{mg} / \mathrm{kg}$, respectively).

Following a small neck incision, a metal cannula (22 gauge, $2.5 \mathrm{~cm}$ in length) was placed in the trachea and firmly secured with a 4.0 silk suture to prevent air leak. The cannula was connected to the mechanical ventilator, after which the animal was paralyzed with pancuronium bromide $(0.1 \mathrm{mg} / \mathrm{kg}$ i.m.). Chest electrodes were placed and the animal's ECG signal was acquired continuously (Hewlett Packard, Palo Alto, CA, U.S.A.) to monitor for cardiovascular stability. The animal was kept on a warm circulating water pad to maintain the body temperature constant at $37^{\circ} \mathrm{C}$.

Institutional review. All procedures involving animals were conducted according to criteria established by the Canadian Council for Animal Care. Approval for the study was obtained from the Animal Care Review Committee of the Hospital for Sick Children Research Institute.

Mechanical ventilation. The animals were air-ventilated with a tidal volume of 10 or $40 \mathrm{~mL} / \mathrm{kg}$ in a randomized manner with a rate of 60 breaths/min and 1:1 inspiratory/expiratory ratio for $60 \mathrm{~min}$. A PEEP $=0$ was applied to the animals ventilated with $40 \mathrm{~mL} / \mathrm{kg}(n=15)$. An additional four newborn animals were ventilated for a total of 180 min with a tidal volume of $40 \mathrm{~mL} / \mathrm{kg}$ and PEEP $=0$. The higher tidal volume with a PEEP $=0$ ventilation strategy has been shown to result in lung injury in the adult rat (20).
The $10 \mathrm{~mL} / \mathrm{kg}$ tidal volume group was placed on a PEEP of $2 \mathrm{~cm} \mathrm{H}_{2} \mathrm{O}$ to avoid lung atelectasis $(n=9)$. Nonventilated newborn animals served as controls $(n=12)$. In pilot experiments, we collected at the end of the ventilation period mixed arterial/venous blood after decapitation for $\mathrm{pH}$ and blood gases measurements. The $\mathrm{pH}$ was $7.31 \pm 0.09$ and $7.55 \pm 0.09$ and the $\mathrm{PCO}_{2}$ was $58 \pm 16$ and $31 \pm 9$ torr for the $10(n=3)$ and $40 \mathrm{~mL} / \mathrm{kg}$ ventilated animals $(n=3)$, respectively.

A custom-made mechanical ventilator, previously described, was used (21) Briefly, the ventilator incorporates a 24-cm-long capillary tube with a very small internal diameter $(0.025 \mathrm{~cm})$ placed between a high-pressure gas source and the animal. The animal is connected to the ventilator via a miniature $\mathrm{Y}$ piece (dead space, $0.02 \mathrm{~mL}$ ) and plastic tubes of low compliance. One tube is for inspiration, the second one is for expiration, and the third is for connection to a pressure transducer in the ventilator for monitoring airway-opening pressure. The expiratory circuit is approximately linear in the flow ranges used and expired volume can be measured by integrating expiratory flow.

Total respiratory system dynamic compliance was measured by recording the ventilator tidal volume (measured as expired volume by the internal pneumotachometer) and peak inspiratory- PEEP (as measured by the internal pressure transducer). The ventilator pressure transducer and pneumotachometer measurements were validated after each experiment with a water manometer and calibrated volume syringe, respectively. Compliance measurements were either normalized to the animals' body weight, or expressed as a percentage of the first measurement obtained immediately after intubation (time zero).

Lung lavage and surfactant determination. Immediately after being killed, all animals underwent a modified whole lung lavage, previously described for adult rats (22). Briefly, the lungs were infused with sterile $0.5 \mathrm{~mL}$ saline and the saline was withdrawn and reinfused two more times. This procedure was repeated a total of three times, and the combined volume of the total lavage was recorded. There were no differences in the total volume of saline infused or recovered after the lavage procedure among the experimental and control groups. Previous studies have shown that this lavage procedure removes more than $90 \%$ of the alveolar surfactant in both normal animals and those with acute lung injury (23).

The total lavage was centrifuged at $150 \mathrm{~g}$ for $10 \mathrm{~min}$ to yield a pellet containing cellular debris. The supernatant was then spun at $40,000 \mathrm{~g}$ for $15 \mathrm{~min}$, yielding a supernatant that represented the small surfactant aggregate fraction. The 40,000 -g pellet was suspended in $2 \mathrm{~mL}$ of $0.15 \mathrm{M}$ saline and represented the large surfactant aggregate fraction.

To measure the total phospholipid pool size and individual surfactant aggregate phospholipid pool sizes, aliquots from the total lavage, $150-\mathrm{g}$ pellet, LA, and SA fractions were organic solvent extracted and phospholipid-phosphorous levels in each of these extracts were determined by using the Duck-Chong phosphorous assay (24). Briefly, $100 \mu \mathrm{L}$ of $10 \%(\mathrm{wt} / \mathrm{vol}$ ) magnesium nitrate in methanol were added to the extracted lipids. After being dried, the samples were ashed in a fume hood on an electric rack for about $1 \mathrm{~min}$. After $1 \mathrm{~mL}$ of $1 \mathrm{M}$ 
$\mathrm{HCl}$ was added, the samples were reheated on a heating block while covered for $15 \mathrm{~min}$ at $95^{\circ} \mathrm{C}$. After cooling, a $66-\mu \mathrm{L}$ aliquot of each sample was added to individual wells of a 96-well plate along with $134 \mu \mathrm{L}$ of a dye consisting of $4.2 \%$ ammonium molybdate in $4.5 \mathrm{M} \mathrm{HCl}$ with $0.3 \%$ malachite green $(1: 3 \mathrm{vol} / \mathrm{vol})$. The absorbency of each sample was read at $650 \mathrm{~nm}$ by using a MKII Titretek Multiscan ELISA plate reader (Flow Laboratories Int., Switzerland) and compared with phosphorus reference standards on the same plate.

Measurement of the surfactant biophysical properties. We used the captive bubble surfactometer technique previously described (25). Briefly, the captive bubble method is an in vitro technique developed for the determination of the surface tension, area, and volume of a bubble with a surfactant film at the air-water interface of the bubble. Changing the pressure within the closed chamber can alter the bubble size and, thus, the surface tension of any insoluble film at the bubble surface.

The instrument consists of a sample chamber constructed from cylindrical glass tubing. A metal piston with a tight O-ring seal is fitted into the glass tubing. The ceiling of the chamber consists of a slightly concave surface of a $1 \%$ agarose gel cylinder attached to the metal piston, generating a completely hydrophilic surface for contact with the bubble. The temperature of the chamber was maintained at $37^{\circ} \mathrm{C}$. We used the spreading technique described in Codd et al. (26), with slight modifications. This technique allowed us to examine the surface activity of very low volumes of surfactant at a relatively high concentration. Briefly the captive bubble chamber ( $1 \mathrm{~mL}$ volume) was filled with a buffered salt solution [0.9\% $\mathrm{NaCl}, 10 \mathrm{mM} \mathrm{N}$-2-hydroxyethylpiperazine- $N$ '-2-ethanesulfonic acid (HEPES), $2.5 \mathrm{mM} \mathrm{CaCl} 2, \mathrm{pH} 6.9$ ], which contained 10\%, by mass, sucrose. The sucrose was added to increase the density of the salt solution to approximately $1.04 \mathrm{~g} / \mathrm{mL}$, above that of the surfactant suspension $(1.01 \mathrm{~g} / \mathrm{mL})$. Two microliters of $10 \mathrm{mg} / \mathrm{mL}$ from each sample was injected into the chamber near its agarose ceiling. The injected surfactant rests against the agarose ceiling at the top of the chamber. A bubble 6-7 $\mathrm{mm}$ in diameter was then created by moving the chamber down relatively to the stationary piston, and drawing air in by means of a small hole in the chamber base.

Calculation of surface tension area and volume. The bubble was recorded continuously throughout the experiment on a video recorder (Sony EVO-9800A recorder (Sony of Canada, Toronto, Ontario, Canada) and Pulnix TM-7EX camera (Pulnix America Inc., Sunnyvale, CA, U.S.A.)). Surface tension, area, and volume were calculated from video images of the bubble height and diameter. Minimum surface tension was obtained when the bubble ceased to flatten and began to decrease in its width upon small compression steps.

Adsorption measurements. Initially, a bubble was introduced into the chamber through a small inlet at the bottom of the chamber. The bubble moves up through the surfactant solution and comes to rest at the agarose surface. The moment the bubble comes to rest and assumes a Laplacian shape was considered to be time zero. Adsorption was assessed by measuring the decrease in surface tension over time.

Quasi-static cycling. After adsorption to the equilibrium surface tension of $\sim 25 \mathrm{mN} / \mathrm{m}$, the bottom inlet of the bubble chamber was sealed and the film at the bubble air-liquid interface was compressed stepwise, by reducing the bubble volume by $10 \%$ at each step and waiting for $10 \mathrm{~s}$ after each step. We conducted four quasi-static cycles with an intercycle delay of $2 \mathrm{~min}$. The waiting periods at each step and the intercycle delays allowed the system to equilibrate. The quasistatic cycles were performed to establish the limits for the volume changes required for the maximum surface tension of approximately $30 \mathrm{mN} / \mathrm{m}$ and the minimum of less than $5 \mathrm{mN} / \mathrm{m}$ for dynamic cycling.

Dynamic cycling. After the four quasi-static cycles, a waiting period of $2 \mathrm{~min}$ was observed and the bubbles were then cycled dynamically at 20 cycles/min by using the approximate volume limits established before. Compression was stopped at the time point when the bubble shape ceased to flatten and the minimum surface tension was achieved.

Lung histology. At completion of the experiments, some lungs were prepared for histologic assessment after airway inflation $\left(10 \mathrm{~cm} \mathrm{H}_{2} \mathrm{O}\right)$ and fixation with formalin. Standard paraffin-blocking sectioning of the lung was used, as previously described (27). The lung slices were stained with hematoxylin and eosin and examined by light microscopy.

Statistical analysis. Values are mean \pm SE. Experimental and control data were compared by one- or two-way ANOVA. Multiple comparisons were done by the Tukey test utilizing the "Number Cruncher" Statistical Software (NCSS, Kaysville, UT, U.S.A.). Significance was accepted at $p<0.05$.

\section{RESULTS}

Mechanical ventilation was associated with an increase in total respiratory system compliance $(p<0.01)$, both in absolute terms, and as a percent increase from time zero values (Fig. 1). These changes were statistically significant $(p<0.05)$ starting from the 10-min time points, for both the 10 and 40 $\mathrm{mL} / \mathrm{kg}$ groups. Furthermore, compliance was greater in the animals ventilated with $40 \mathrm{~mL} / \mathrm{kg}$ tidal volume compared with $10 \mathrm{~mL} / \mathrm{kg}$ (Fig. 1).

The alveolar surfactant composition changed with mechanical ventilation. After $60 \mathrm{~min}$ of $10 \mathrm{~mL} / \mathrm{kg}$ tidal volume ventilation, the total surfactant (Fig. $2 A, P<0.05$ ) and LA fraction (Fig. $2 B, p<0.01$ ) significantly increased, whereas the SA fraction decreased (Fig. $2 C, p<0.05$ ).

A $40 \mathrm{~mL} / \mathrm{kg}$ tidal volume resulted in a similar and significant increase in total surfactant (Fig. $3 A, p<0.05$ ) after 60 , but not 180 min ventilation. The LA fraction was significantly greater than the control values at $180 \mathrm{~min}$ of ventilation (Fig. $3 B, p<$ 0.05 ) and the SA fraction was not altered by mechanical ventilation (Fig. 3C).

Significant changes in the surfactant surface-tension properties were observed after ventilation with a tidal volume of 40 $\mathrm{mL} / \mathrm{kg}$. The film adsorption at $1 \mathrm{~s}$ for the nonventilated rats was $34 \pm 6 \mathrm{mN} / \mathrm{m}$ and not statistically different from the values measured in animals ventilated for $30 \mathrm{~min}$ and $60 \mathrm{~min}$ with a tidal volume of $40 \mathrm{~mL} / \mathrm{kg}(26 \pm 2,36 \pm 5 \mathrm{mN} / \mathrm{m}$, respectively). In these animals, further film adsorption measurements at 1 and 5 min were similar to the 1 -s values. 


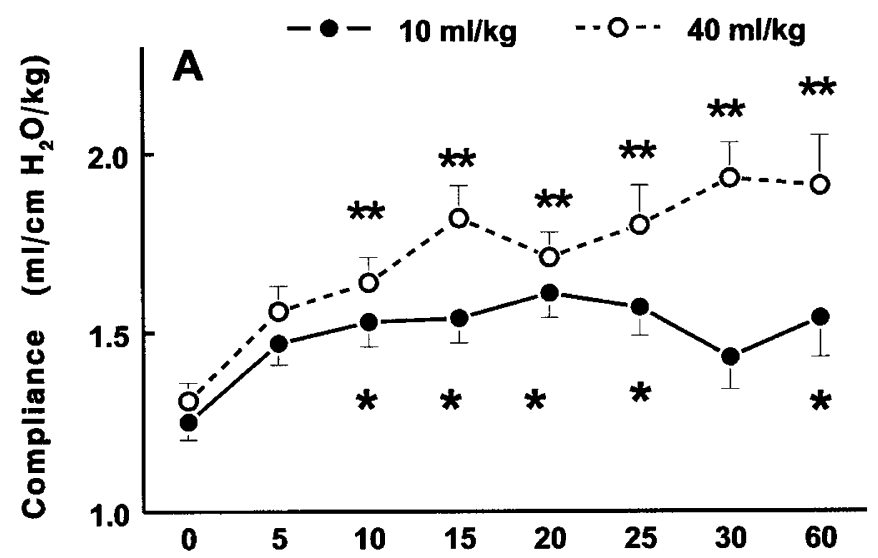

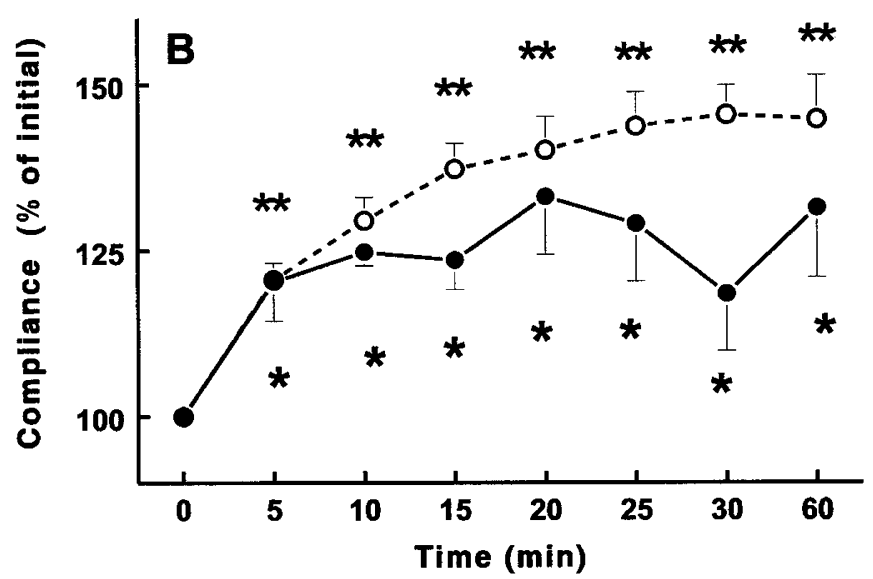

Figure 1. Absolute values $(A)$ and percentage of the measurement obtained immediately after ventilation began $(B)$ for total respiratory system compliance in animals ventilated with $10(n=9)$ and $40 \mathrm{~mL} / \mathrm{kg}$ tidal volume $(n=15) .{ }^{*} p$ $<0.05$ and ${ }^{* *} p<0.01$ by one-way ANOVA, as compared with time 0 values.

The minimum surface tension measured under dynamic cycling conditions was significantly higher in the animals ventilated with a tidal volume of $40 \mathrm{~mL} / \mathrm{kg}$ for $60 \mathrm{~min}$, as compared with the nonventilated values (Fig. 4). In keeping with the worsening surface-tension properties and decreased total surfactant, the lung dynamic compliance decreased past $60 \mathrm{~min}$ and at $180 \mathrm{~min}$ was no longer significantly different from time zero values (Fig. 5).

Figure 6 shows representative lung histology of animals ventilated for $60 \mathrm{~min}$ with either 10 or $40 \mathrm{~mL} / \mathrm{kg}$ tidal volumes. No significant gross changes in the lung parenchyma of ventilated animals were observed, as compared with controls.

\section{DISCUSSION}

In the newborn rat, mechanical ventilation with tidal volumes above the physiologic range induced a short-lived increase in total lung surfactant and improved total respiratory compliance. Such effect was observed when either $10 \mathrm{~mL} / \mathrm{kg}$, or a higher and potentially more injurious tidal volume ( 40 $\mathrm{mL} / \mathrm{kg}$ PEEP $=0$ ) was used. The lung surfactant biophysical properties were adversely affected by $40 \mathrm{~mL} / \mathrm{kg}$ tidal volume
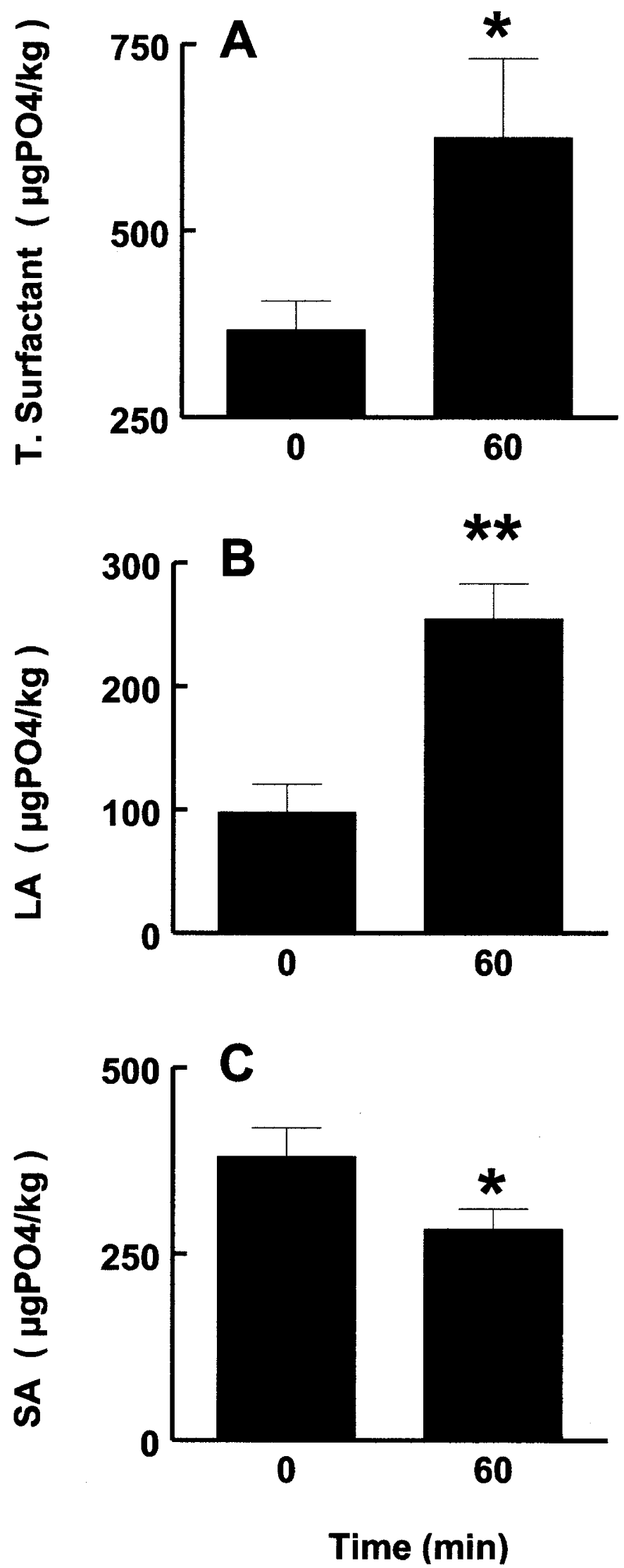

Figure 2. (A) Total surfactant, $(B)$ large aggregates $(L A)$, and $(C)$ small aggregates $(S A)$ for the control nonventilated $(n=9)$, and $10 \mathrm{~mL} / \mathrm{kg}$ tidal volume 60 min ventilated animals $(n=5)$. $* p<0.05, * * p<0.01$ by one-way ANOVA, as compared with control values (time $=0 \mathrm{~min}$ ). 

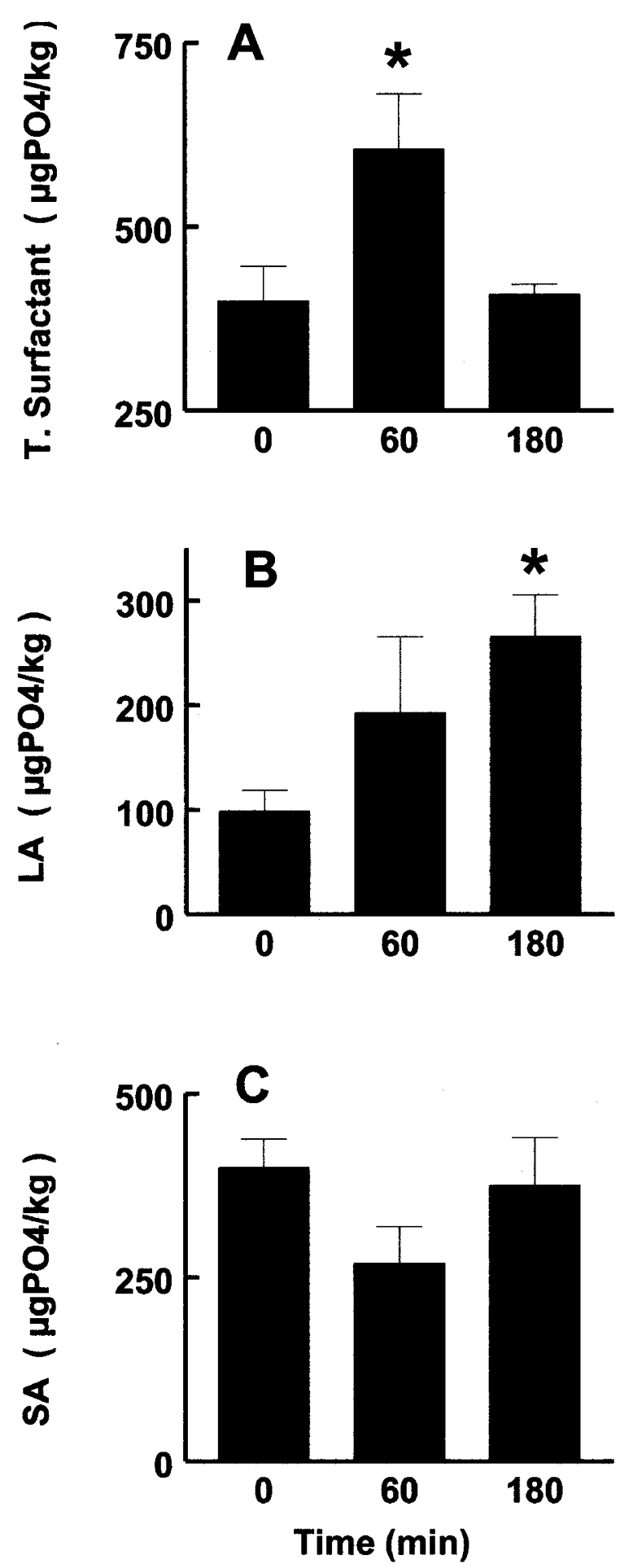

Figure 3. (A) Total surfactant, $(B)$ large aggregates $(L A)$, and $(C)$ small aggregates $(S A)$ for the control nonventilated $(n=9)$, and $40 \mathrm{~mL} / \mathrm{kg}$ tidal volume $60(n=4)$ and $180 \min (n=5)$ ventilated animals. ${ }^{*} p<0.05$ by one-way ANOVA, as compared with control values (time $=0 \mathrm{~min}$ ).

ventilation and the total surfactant content at $180 \mathrm{~min}$ of ventilation was no longer different from the measured in the nonventilated animals.

In the lung, the epithelial type II cells secrete surfactant into the alveoli as lamellar bodies. These bodies unravel into multilaminar and lipid-protein tubular myelin-like structures con-

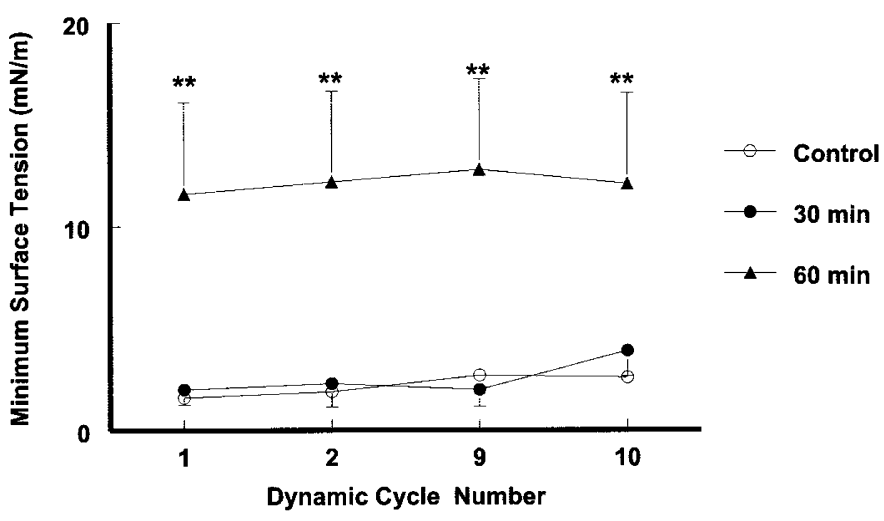

Figure 4. Minimum surface tension measured during dynamic cycling (20 cycles/min) in lung lavage material from nonventilated controls $(n=4)$, 30 -min $(n=4)$, and 60-min $(n=4)$ ventilated animals with a tidal volume of $40 \mathrm{~mL} / \mathrm{kg}$. The minimum surface tensions were taken from the cycles numbers $1,2,9$, and $10 .{ }^{* *} p<0.01$ by two-way ANOVA, as compared with control values.

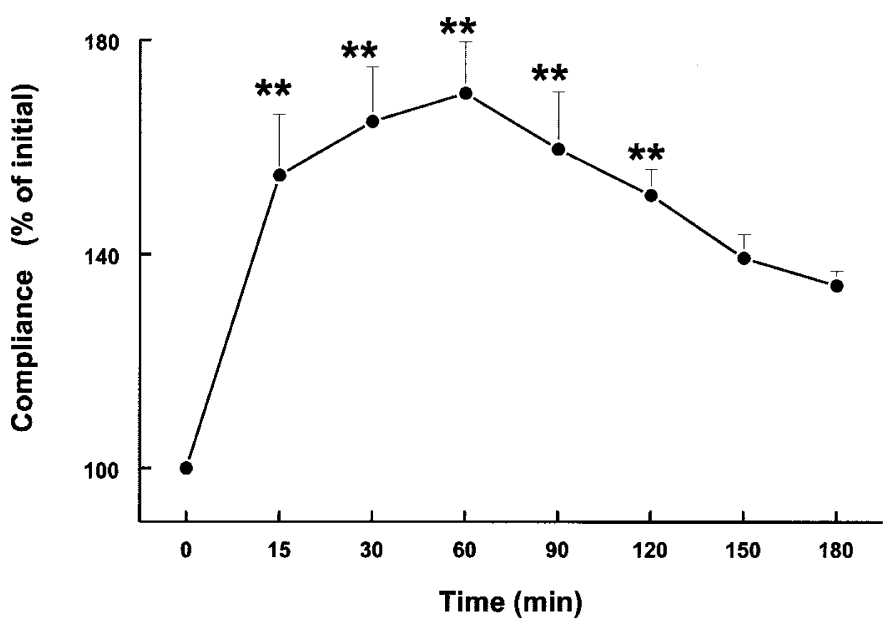

Figure 5. Total respiratory system compliance expressed as percentage of time zero values for animals ventilated with $40 \mathrm{~mL} / \mathrm{kg}$ for $180 \mathrm{~min}(n=4) .{ }^{* *} p$ $<0.01$ by one-way ANOVA, as compared with time 0 values.

taining SP-A, -B, and -C. These forms are referred to as large aggregates and can be separated from the lavage via high speed centrifugation (16). The surface tension-lowering properties of surfactant are related to this LA pool within the airspace. During respiration, LA are converted into smaller, vesicular lipid structures called SA that have poor surface tensionlowering properties $(28,29)$. Previous in vitro and in vivo studies have shown that phasic alveolar stretch induced by different tidal volumes is an important mediator of LA conversion. In addition, mechanical stretch induces expression of SP-C in fetal lung cells (30).

In this study, we have documented that the increase in alveolar surfactant pools induced by ventilation with $10 \mathrm{~mL} / \mathrm{kg}$ and $40 \mathrm{~mL} / \mathrm{kg}$ tidal volume is associated with an increase in the LA subfraction. Because LA represents the functionally active forms of alveolar surfactant, these changes likely explain the initial improvement in lung compliance observed in these animals.

In adult animals, the available data also suggest that alveolar distention results in surfactant release and/or secretion. For 
Non - Ventilated

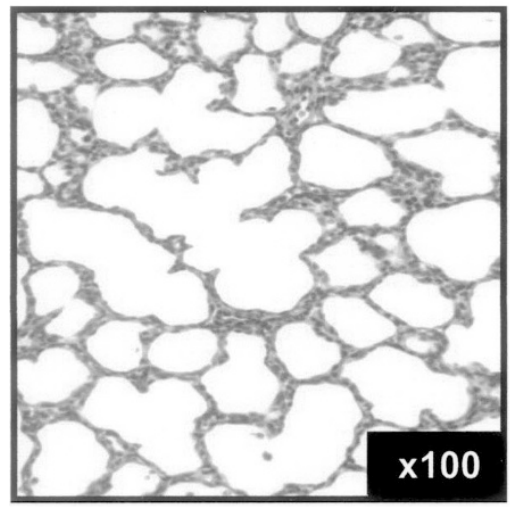

$\mathrm{TV}=10 \mathrm{ml} / \mathrm{kg}$

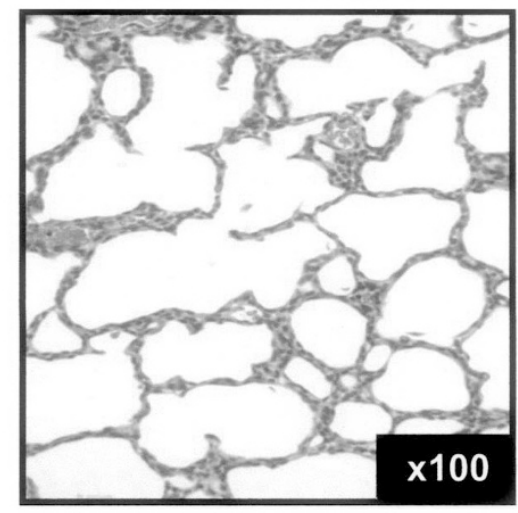

$\mathrm{TV}=\mathbf{4 0 ~} \mathrm{ml} / \mathrm{kg}$

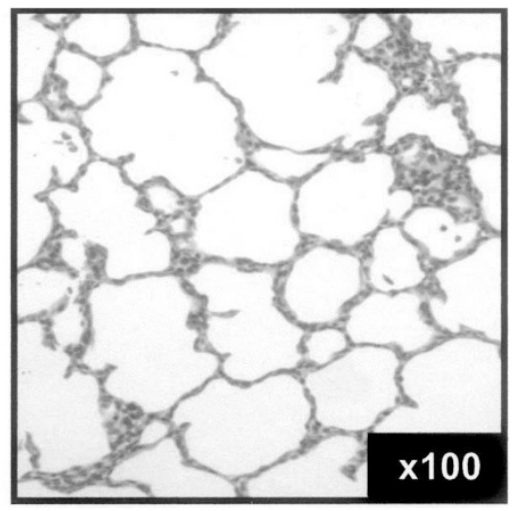

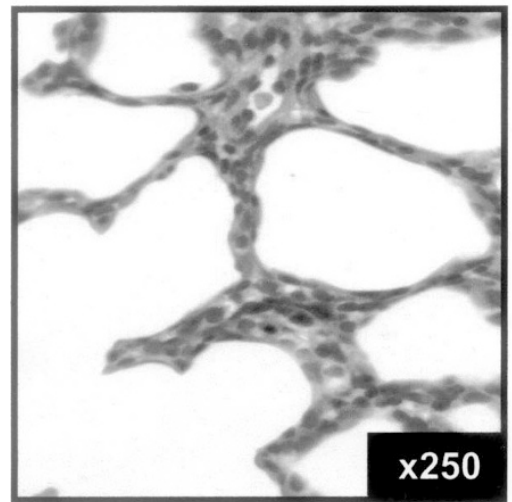
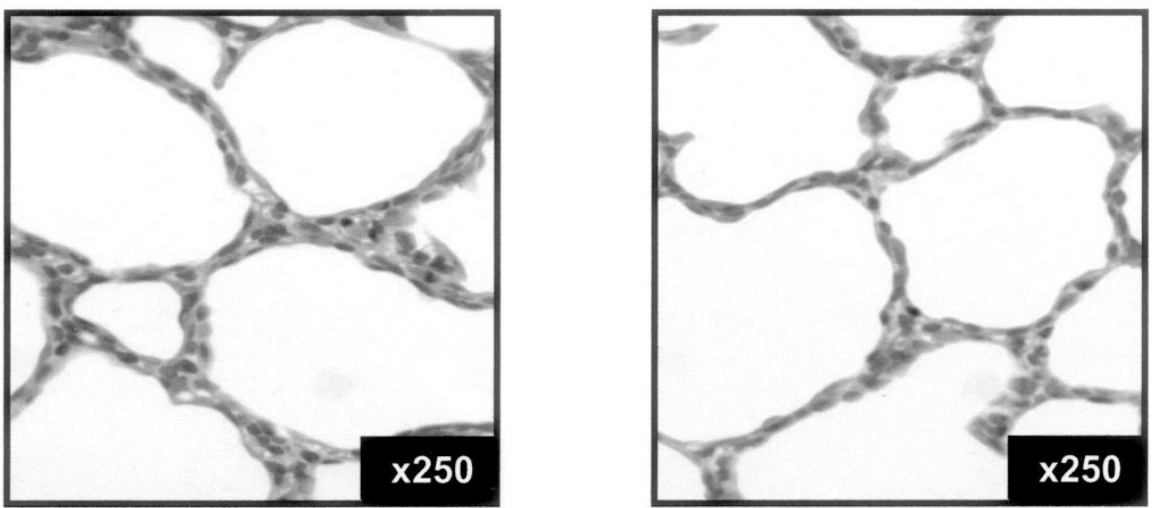

Figure 6. Representative hematoxylin and eosin-stained lung histology of control and 60-min ventilated (10 and $40 \mathrm{~mL} / \mathrm{kg}$ tidal volumes) newborn rats. Magnification $100 \times$ and $250 \times$.

example, stretching of alveolar epithelial cells in vitro resulted in surfactant secretion (1), and, in adult rats, exercise (swimming) was associated with an increase in alveolar surfactant pools (2). Furthermore, $15 \mathrm{~min}$ of ventilation with high tidal volume caused release and/or secretion of surfactant (3), and in isolated perfused lungs given a single high tidal volume breath, surfactant pools were increased in rat lung lavage (31).

Other animal studies, however, have shown that, in spite of this stretch-induced increase in surfactant content, the isolated lung compliance after high tidal volume ventilation actually decreased (4). As shown in this study, this discrepancy is likely related to the fact that, although the total surfactant and its LA subfraction content initially increase, its surface tensionlowering properties are altered by ventilation with a high tidal volume. In fact, in the adult rat isolated lung preparation high tidal volume ventilation adversely affects pulmonary surfactant (32).

In this study, we chose to ventilate one group of animals with $10 \mathrm{~mL} / \mathrm{kg}$ tidal volume, as previously reported in a clinical study of healthy term neonates (17). In addition, a doubling of the physiologic tidal volume is commonly used for recruitment maneuvers in ventilated neonates. Indeed, our protocol may well be applicable to the effects of recruitment maneuvers often used with mechanical ventilation. Whether recruitment maneuvers for mechanically ventilated neonates are of clinical benefit is debatable (33). In healthy neonates, recruitment seems to improve lung compliance (17), yet, lung recruitment at birth does not improve the response to surfactant in immature lambs, and may have an adverse effect on lung function and morphology (34).

Although we documented in the present study an initial increase in compliance and surfactant pools, mechanical ventilation of the newborn with a high tidal volume and PEEP = 0 for longer than $60 \mathrm{~min}$ alters the surfactant biophysical properties and likely results in lung injury. These changes can occur after a short exposure to mechanical ventilation. This is best illustrated by the recent evidence from Gajic et al. (35), where adult rats ventilated with a tidal volume of $40 \mathrm{~mL} / \mathrm{kg}$ and PEEP $=0$ for as little as $30 \mathrm{~min}$ showed significant lung parenchymal cell injury. The lung injury in the latter study (35), was only evident utilizing a cell membrane impermeable fluorescent marker and confocal microscopy. Thus, the normal appearance of the ventilated newborn lungs in this study does not exclude the possibility of significant injury at the cellular level.

The preterm lung is highly susceptible to injury during resuscitation or more chronic mechanical ventilation because the gas volumes per kilogram body weight of the lungs are 
small (36). Lung injury can be initiated in the immediate neonatal period if excessive tidal volumes are used during resuscitation and ventilation (33). Further evaluation of intermittent ventilation with a higher than physiologic tidal volume on the lung compliance and surfactant content of diseased and immature lungs is warranted. Such data will be of clinical relevance toward addressing the potential benefit of the use of lung recruitment maneuvers in newborns.

In summary, we demonstrated for the first time that total surfactant increases in healthy term newborn rats ventilated with a tidal volume higher than physiologic. This is associated with a significant but short-lived increase in total respiratory lung compliance. We speculate that the beneficial improvement in lung function in neonates after recruitment maneuvers with tidal volumes slightly higher than physiologic for a short duration is related to an increase in lung surfactant content.

\section{REFERENCES}

1. Wirtz HR, Dobbs LG 1990 Calcium mobilization and exocytosis after one mechanical stretch of lung epithelial cells. Science 250:1266-1269

2. Nicholas TE, Power JH, Barr HA 1982 Surfactant homeostasis in the rat lung during swimming exercise. J Appl Physiol 53:1521-1528

3. Nicholas TE, Barr HA 1983 The release of surfactant in rat lung by brief periods of hyperventilation. Respir Physiol 52:69-83

4. Veldhuizen RA, Welk B, Harbottle R, Hearn S, Nag K, Petersen N, Possmayer F 2002 Mechanical ventilation of isolated rat lungs changes the structure and biophysical properties of surfactant. J Appl Physiol 92:1169-1175

5. Veldhuizen RA, Ito Y, Marcou J, Yao LJ, McCaig L, Lewis JF 1997 Effects of lung injury on pulmonary surfactant aggregate conversion in vivo and in vitro. Am J Physiol 272:L872-L878

6. Dreyfuss D, Saumon G 1998 Ventilator-induced lung injury: lessons from experimental studies. Am J Respir Crit Care Med 157:294-323

7. Parker JC, Hernandez LA, Peevy KJ 1993 Mechanisms of ventilator-induced lung injury. Crit Care Med 21:131-143

8. Kavanagh BP, Slutsky AS 1999 Ventilator-induced lung injury: more studies, more questions. Crit Care Med 27:1669-1671

9. Hickling KG, Henderson SJ, Jackson R 1990 Low mortality associated with low volume pressure limited ventilation with permissive hypercapnia in severe adult respiratory distress syndrome. Intensive Care Med 16:372-377

10. Hickling KG, Walsh J, Henderson S, Jackson R 1994 Low mortality rate in adult respiratory distress syndrome using low-volume, pressure-limited ventilation with permissive hypercapnia: a prospective study. Crit Care Med 22:1568-1578

11. Mariani G, Cifuentes J, Carlo WA 1999 Randomized trial of permissive hypercapnia in preterm infants. Pediatrics 104:1082-1088

12. Stewart TE, Meade MO, Cook DJ, Granton JT, Hodder RV, Lapinsky SE, Mazer CD, McLean RF, Rogovein TS, Schouten BD, Todd TR, Slutsky AS 1998 Evaluation of a ventilation strategy to prevent barotrauma in patients at high risk for acute respiratory distress syndrome. Pressure- and Volume-Limited Ventilation Strategy Group. N Engl J Med 338:355-361

13. Brochard L, Roudot-Thoraval F, Roupie E, Delclaux C, Chastre J, FernandezMondejar E, Clementi E, Mancebo J, Factor P, Matamis D, Ranieri M, Blanch L, Rodi G, Mentec H, Dreyfuss D, Ferrer M, Brun-Buisson C, Tobin M, Lemaire F 1998 Tidal volume reduction for prevention of ventilator-induced lung injury in acute respiratory distress syndrome. The Multicenter Trail Group on Tidal Volume reduction in ARDS. Am J Respir Crit Care Med 158:1831-1838

14. Brower RG, Shanholtz CB, Fessler HE, Shade DM, White Jr P, Wiener CM, Teeter JG, Dodd-o JM, Almog Y, Piantadosi S 1999 Prospective, randomized, controlled clinical trial comparing traditional versus reduced tidal volume ventilation in acute respiratory distress syndrome patients. Crit Care Med 27:1492-1498

15. Amato MB, Barbas CS, Medeiros DM, Magaldi RB, Schettino GP, Lorenzi-Filho G, Kairalla RA, Deheinzelin D, Munoz C, Oliveira R, Takagaki TY, Carvalho CR 1998 Effect of a protective-ventilation strategy on mortality in the acute respiratory distress syndrome. N Engl J Med 338:347-354

16. The Acute Respiratory Distress Syndrome Network 2000 Ventilation with lower tidal volumes as compared with traditional tidal volumes for acute lung injury and the acute respiratory distress syndrome. N Engl J Med 342:1301-1308

17. Ratjen F, Zinman R, Stark AR, Leszczynski LE, Wohl ME 1989 Effect of changes in lung volume on respiratory system compliance in newborn infants. J Appl Physiol 67:1192-1197

18. Sanchez-Esteban J, Cicchiello LA, Wang Y, Tsai SW, Williams LK, Torday JS, Rubin LP 2001 Mechanical stretch promotes alveolar epithelial type II cell differentiation. J Appl Physiol 91:589-595

19. Cotten M, Clark RH. 2001 The science of neonatal high-frequency ventilation. Respir Care Clin N Am 7:611-631

20. Nakamura T, Malloy J, McCaig L, Yao LJ, Joseph M, Lewis J, Veldhuizen R 2001 Mechanical ventilation of isolated septic rat lungs: effects on surfactant and inflammatory cytokines. J Appl Physiol 91:811-820

21. Volgyesi GA, Tremblay LN, Webster P, Zamel N, Slutsky AS 2000 A new ventilator for monitoring lung mechanics in small animals. J Appl Physiol 89:413-421

22. Malloy JL, Veldhuizen RA, Lewis JF 2000 Effects of ventilation on the surfactant system in sepsis-induced lung injury. J Appl Physiol 88:401-408

23. Veldhuizen RA, Marcou J, Yao LJ, McCaig L, Ito Y, Lewis JF 1996 Alveolar surfactant aggregate conversion in ventilated normal and injured rabbits. Am J Physiol 270:L152-L158

24. Duck-Chong CG 1979 A rapid and sensitive method for determining phospholipid phosphorus involving digestion with magnesium nitrate. Lipids 14:492-497

25. Palmer D, Schurch S, Belik J 2000 Effect of budesonide and salbutamol on surfactant properties. J Appl Physiol 89:884-890

26. Codd JR, Schurch S, Daniels CB, Orgeig S 2002 Torpor-associated fluctuations in surfactant activity in Gould's wattled bat. Biochim Biophys Acta 1580:57-66

27. Belik J, Davidge ST, Zhang W, Pan J, Greer JJ 2003 Airway smooth muscle changes in the nitrofen-induced congenital diaphragmatic hernia rat model. Pediatr Res 53:737-743

28. Veldhuizen RA, Hearn SA, Lewis JF, Possmayer F 1994 Surface-area cycling of different surfactant preparations: SP-A and SP- B are essential for large-aggregate integrity. Biochem J 300:519-524

29. Veldhuizen RA, Yao LJ, Lewis JF 1999 An examination of the different variables affecting surfactant aggregate conversion in vitro. Exp Lung Res 25:127-141

30. Nakamura T, Liu M, Mourgeon E, Slutsky A, Post M 2000 Mechanical strain and dexamethasone selectively increase surfactant protein $\mathrm{C}$ and tropoelastin gene expression. Am J Physiol 278:L974-L980

31. Nicholas TE, Power JH, Barr HA 1982 The pulmonary consequences of a deep breath. Respir Physiol 49:315-324

32. Veldhuizen RA, McCaig LA, Akino T, Lewis JF 1995 Pulmonary surfactant subfractions in patients with the acute respiratory distress syndrome. Am J Respir Crit Care Med 152:1867-1871

33. Auten RL, Vozzelli M, Clark RH 2001 Volutrauma. What is it, and how do we avoid it? Clin Perinatol 28:505-515

34. Bjorklund LJ, Ingimarsson J, Curstedt T, Larsson A, Robertson B, Werner O 2001 Lung recruitment at birth does not improve lung function in immature lambs receiving surfactant. Acta Anaesthesiol Scand 45:986-993

35. Gajic O, Lee J, Doerr CH, Berrios JC, Myers JL, Hubmayr RD 2003 Ventilatorinduced cell wounding and repair in the intact lung. Am J Respir Crit Care Med 167:1057-1063

36. Jobe AH, Ikegami M 1998 Mechanisms initiating lung injury in the preterm. Early Hum Dev 53:81-94 